\title{
On Rescissions in Executive Stock Options ${ }^{1}$
}

\author{
Menachem Brenner Rangarajan Sundaram David Yermack
}

April 15, 2002

\footnotetext{
${ }^{1}$ We are very grateful to Viral Acharya for substantial technical help, and to Nikolay Halov for research assistance. All three authors are in the Department of Finance, Stern School of Business, New York University, New York, NY 10012. Their e-mail addresses are mbrenner@stern.nyu.edu, rsundara@stern.nyu.edu, and dyermack@stern.nyu.edu.
} 


\begin{abstract}
We study executive stock options that permit the option holder to rescind an exercise decision, returning the shares acquired to the company and obtaining a refund of the exercise price. Rescissions occurred at a number of U.S. companies in 2000 after the large decline in internet stocks, and have been widely condemned as a weakening of incentives. To the contrary, we find that in many situations rescindable options dominate ordinary options by delivering greater value and stronger incentives to the employee at a lower cost to the firm. The attractiveness of rescinable options arises as a consequence of the income tax treatment of most executive stock options in the U.S.
\end{abstract}




\section{Introduction}

In the last decade, stock options have become an increasingly important component of employee compensation in the United States, accounting, by some measures, for over $50 \%$ of total executive pay (Murphy [15]). A common argument advanced in favor of these instruments is that they align shareholder interests and employee incentives by tying compensation to share price performance. Nonetheless, empirical and anecdotal evidence suggests that companies protect option-holding employees from the effects of declining share prices. Previous work has investigated the prevalence and optimality of one such tactic, that of repricing, in which the strike prices of previously-issued options are lowered to bring the options closer to the money. ${ }^{1}$ This paper examines a more recent practice known as rescission that is actuated by similar considerations and has received harsh criticism in the financial press. ${ }^{2}$

Unlike repricing, which takes place prior to the option's exercise and aims to restore value to deep out-of-the-money options, rescission takes place after the exercise of stock options by employees. In a rescission, shares received by the employee from exercise of the options are returned to the company in exchange for a refund of the strike price. (This presumes the shares received from exercise were not sold in the interim; rescission is not possible if the shares were sold.) Rescission therefore negates exercise decisions that proved poor ex-post, that is, those in which exercise was followed by a steep decline in the stock price. In some cases, rescission also permits employees to have their original options restored with terms unchanged.

A principal motivation driving rescissions is the tax treatment of option exercise decisions. Under U.S. law, the depth in-the-money (or "spread") of the option at exercise is taxed as ordinary income in the year of exercise, regardless of whether the shares obtained by the exercise were subsequently sold during that year. ${ }^{3}$ Thus, for example, an employee exercising options with a strike of $\$ 10$ when the stock price is $\$ 80$ must pay income taxes on the amount $\$(80-10)=\$ 70$; at a marginal tax rate of (say) $40 \%$, this amounts to a tax of $\$ 28$ per share. However, if the option exercise decision is rescinded before the end of the tax year in which exercise occurred, then, for tax purposes, it is as if the exercise never happened, and no taxes are owed by the employee. Thus, where the exercise decision is followed by a steep drop in the price of the stock, rescission offers a substantial benefit to the employee. Indeed, in the cases reported in the financial press, the shares held by employees were, at the time of rescission, typically worth less even than the taxes due on account of the exercise. (This would have been the case in our example if share prices fell below $\$ 28$.) Apart from the presumed boost in employee morale, rescissions also offered a direct benefit to the company in many cases, since employees had borrowed money from the company to pay the strike price for their options.

Rescissions have come under fire from the financial press and large institutional investors as a symptom of poor corporate governance. Superficially at least, they appear to be vulnerable 
to the commonly-voiced criticism that they reward employees when share prices fall. An option whose exercise decision may be rescinded is analogous to a standard call option plus a contingent put option which comes into existence if the call is exercised, and which gives the employee the right to sell the stock back to the company. (Since rescission also cancels the original tax bill, the strike price on this put is equal to the original strike price plus the taxes due on account of exercise of the call.) Since the contingent put protects employees from the adverse effects of share price declines, it is argued that rescissions weaken-and maybe even remove-the alignment of interests between employees and shareholders that the options were intended to provide in the first place. ${ }^{4}$

This paper examines whether rescissions are really the corporate giveaway they appear to be at first sight. We compare options whose exercise decisions may be rescinded ("rescindable options") to ones where rescission is not an alternative ("standard options"). We focus especially on two questions. First, from a quantitative standpoint, how do the values of rescindable options (to the employee and the company) compare with standard options? Second, how do rescindable options' incentive properties compare with those of standard options?

Despite widepread condemnation of rescissions by experts and commentators, we find it surprisingly difficult to make a case against them. We show that the gross economic cost to the company of writing rescindable options is less than or equal to the cost of standard options; the economic value received by employees is higher from rescindable options than standard ones; and incentive properties, as measured by the option value sensitivities to the underlying stock price, are generally superior for rescindable options compared to standard ones. Nonetheless, we find there are circumstances where standard options may be preferable for the company, though the reasons are subtle.

What drives these conclusions? A simple example will make the intuition transparent. Consider a one-period option on a stock that is currently at 100 and that will be at 110 or 90 after one period. Assume the risk-free rate of interest is zero and the marginal tax rate of the option holder is $40 \%$. Suppose finally that the option strike price is 100 . The holder of a rescindable option in this setting faces two choices:

- Exercise now, retain the stock, and rescind the decision if the price of 90 is reached.

- Exercise after one period.

Under the first strategy, there is no tax consequence of exercise. Thus, taking into account the 100 paid today, the net payoffs to the option holder after one period are

$\left\{\begin{array}{cl}10, & \text { if the stock price moves to } 110 \\ 0, & \text { if the stock price moves to } 90\end{array}\right.$ 
The second strategy generates the same gross payoffs at maturity. However, there are taxes due upon exercise, so the net payoffs to the option holder are

$$
\begin{cases}6, & \text { if the stock price moves to } 110 \\ 0, & \text { if the stock price moves to } 90\end{cases}
$$

while the taxes paid are 4 if the price goes to 110 and zero otherwise. Clearly the first strategy dominates so the holder of a rescindable option will exercise right away and receive the payoffs (1.1). On the other hand, it is easy to see that for the holder of a standard option, the optimal strategy is to wait until maturity, so the payoffs received are given by (1.2). ${ }^{5}$ Finally, note that the gross economic cost of the two options to the company is the same, since the gross payoffs received by the employee from the compensation package are the same in the two cases.

This example illustrates three fundamental points that we show hold more generally. First, the ability to rescind option exercise decisions has a significant impact on the optimal early-exercise strategy. Second, the optimal exercise strategy reduces the holder's tax bill under rescindable options, thus benefitting the option holder; in some cases, this may also lower the gross economic cost to the company compared to a standard option. Third, the incentive features provided by the compensation package (e.g., the convexity of final payoffs) are not eliminated by allowing rescission and, indeed, are typically strengthened; in the example above, for instance, one unit of a standard option is equivalent to to only 0.60 units of a rescindable option.

All of this suggests that standard options may actually be dominated by rescindable options, which is the exact opposite of the criticism motivating our analysis. We identify specific conditions under which this conclusion is, in fact, correct. In general, however, the comparison is complicated by an additional factor: the tax shield obtained by the company. If the tax shield were based on the economic cost of writing the option, then rescindable options would typically be superior to standard options. However, under current law, the tax shield is based on the depth in-the-money of the option at exercise. Since depth-in-the-money at exercise will, in general, be higher for standard options (as the example above illustrates), standard options provide a larger tax-shield, so the net cost of the standard option will be typically lower for the company if it is profitable and pays income taxes.

This larger tax shield does not, of course, mean much by itself. If the employee's marginal tax rate is higher than the company's, the tax savings accruing to the employee from rescindable options would be greater than the tax shield lost to the company. This would enable a Pareto-improving transfer (for example, a reduction in some other component of the employee's compensation) if rescindable options were used. Such "gaming" of tax laws to exploit marginal tax rate differentials between employer and employee has been documented in related contexts (Matsunaga, Shevlin and Shores [14]). Too, as noted above, rescindable options generally have superior incentive features, which offset at least partially their lower corporate tax shields. Stan- 
dard options become a superior alternative only if the tax rate differential is negative and the added incentive effects are insufficient to compensate for this difference.

The analysis above presumes that rescissions cancel the tax bill from an earlier option exercise, as appears to be currently permitted by tax laws (see Section 7). We re-work our analysis to study the effects of a change in tax law that would require a rescinding employee to remain liable for the taxes from the original exercise. We find that under some conditions (notably, low interest rates), this change does not have a substantial impact on exercise behavior or option values, leaving rescindable options generally superior to standard options. At high interest rates, however, rescindable options do not appear as attractive.

Two final points about the analysis bear emphasis. First, our results occur in a setting which would likely be looked upon with particular disfavor by critics of rescission: one where employees may themselves choose without restraint whether to rescind their option exercises. This makes it more striking that we find rescissions can benefit the company as well as the employee. Second, as in all valuation exercises, specific assumptions are required to keep the framework tractable. Thus, while our qualitative conclusions on the unexpected positive properties of rescindable options will not change, some caution should obviously be exercised in judging the quantitative nature of our results.

The remainder of this paper is organized as follows. Section 2 reviews the related literature on exotic features of option compensation schemes. Sections 3-6 present our comparison of rescindable vs standard options. Section 7 discusses existing tax treatment of option exercise in various countries. Section 8 concludes.

\section{Literature Review}

The academic literature on executive compensation schemes is vast. Among the issues that have been the focus of recent research are: the valuation of executive stock options (Rubinstein [16]); the effect of reporting costs on the use of stock options (Matsunaga [13]); the effectiveness of options as a means of compensation (Yermack [20]); the timing of option awards (Yermack [21]); and the price impact of early-exercise decisions (Carpenter and Remmers [4], Seyhun [18]).

Most closely related to the present paper is the literature on the "resetting" or "repricing" of previously-issued stock options. As with rescission, repricing is a practice associated mostly with corporations that have experienced steep share price declines. However, unlike rescission which takes place after the option's exercise, repricing takes place prior to the exercise decision, lowering the strike price of options to bring them closer to the money. The incidence of repricing by corporations in financial distress is examined in Gilson and Vetsuypens [8], while repricing after the stock market crash of 1987 is studied by Saly [17]. Empirical analyses of repricing in 
more "normal" circumstances may be found in Brenner, Sundaram, and Yermack [3], Chance, Kumar, and Todd [5], and Chidambaram and Prabhala [6]. In theoretical work, Acharya, John, and Sundaram [2] employ an agency model to examine potential merits of repricing ; they find that allowing for some amount of repricing in option grants is, in general, optimal.

Other compensation schemes used in practice involve also non-standard features. Hemmer, Matsunaga, and Shevlin [10],[11] analyze "reload" options. In a reload option, at exercise time the option holder receives both the shares paid for by the strike price, as well as additional at-the-money options. Johnson and Tian [12] examine six compensation schemes with nonstandard aspects. These include premium options, in which the strike price is set so that the option is out-of-the-money on the grant date; preformance-vested options, which do not become unexerciseable unless the stock return crosses a minimum threshold level; purchased options, in which the employee pays a fraction of the strike price at the time of the option grant and which is lost if the option is never exercised; indexed options, in which the strike price is related to an industry index; reload options, as described above; and options that may be repriced, also as mentioned above.

\section{The Basic Framework}

This section introduces the basic framework and notation that we use to analyse rescindable options. The two categories of options introduced here are compared first in a special case of interest in Section 4 and then more generally in Section 5. Finally, an important variant of the framework introduced here is discussed in Section 6.

We consider a model with horizon $T$. Time is denoted $t$, with time 0 denoting the initial point and time $T$ the terminal date. An employee stock option award is made at time 0 ; the option has a strike of $K$ and expires at time $T$. The time- $t$ stock price of the firm is denoted $S_{t}$. The option is American in style so that it can be exercised at any point over the horizon. The constant risk-free rate of interest (continuously-compounded) is denoted $r$. To keep matters simple, we assume that the stock pays no dividends during the option's life. ${ }^{6}$

Exercise of the option triggers a potential income tax liability for the option holder. If exercise occurs at time $t$ at a stock price of $S_{t}$, then on date $T$, the employee owes taxes in the amount of $\tau \cdot\left(S_{t}-K\right)^{+}$, where $\tau \in[0,1)$ is the marginal income tax rate of the employee, and $x^{+}=$ $\max \{0, x\}$. Whether this tax has actually to be paid at $T$ depends on whether the option exercise decision is rescinded, as we now explain.

We consider two cases. One involves a standard option, where no reversal of the exercise decision is possible; in this case, the employee must pay the taxes owed at $T$. In the other case, the employee may rescind the exercise decision on date $T$. (We term this case a "rescindable 
option.") Specifically, suppose that the option had been exercised on date $t \leq T$ when the stock price was $S_{t}$. Then, on date $T$, the employee has the choice of rescinding this exercise decision. If the decision is rescinded, the employee returns one unit of the stock to the company and receives the strike price $K$ in exchange; in addition, rescission also eliminates the employee's tax liability $\tau \cdot\left(S_{t}-K\right)^{+}$. If the exercise decision is not rescinded, then the tax bill of $\tau \cdot\left(S_{t}-K\right)^{+}$is due on date $T$.

Our objective is compare standard and rescindable options from the standpoints of cost and incentive features. To this end, we use risk-neutral techniques to identify option values and option sensitivities. So suppose that a risk-neutral measure exists (with respect to the risk-free rate as numeraire). All references to expectations in the sequel are with respect this measure. We denote time- $t$ expectations under this measure by $E_{t}^{*}[\cdot]$.

Two comments on this structure are in order before proceeding further. The first concerns the empirical structure of employee stock option awards. Employee stock options are typically awarded at-the-money and have a vesting period during which they may not be exercised. To keep the problem tractable, we do not impose such a no-exercise period. However, in partial compensation, we also do not require $S_{0}=K$, so the option may be in-, at-, or out-of-themoney at time 0 ; thus, the period $[0, T]$ may be thought of as the post-vesting option life. Our model also simplifies matters by equating the tax/rescission period and the option's life. This enables us to provide a sharp characterization of the trade-offs that rescission introduces to the exercise decision (see Sections 4 and 5 below). Reality is more complex: option awards have a typical maturity of 10 years, and rescissions can only be made in the same tax year in which exercise occurs. Introducing multiple tax periods into our model complicates the valuation exercise enormously, but intuition suggests strongly that it will leave the qualitative nature of our conclusions unaffected, since the forces driving the trade-offs in early exercise remain largely the same.

A second point concerns the use of risk-neutral pricing techniques. Valuation using these techniques involves an implicit assumption of hedgeability of the option using the underlying stock. This may reasonably be presumed to hold for the shareholders, so option values obtained this way provide a useful approximation of the cost of the option to the shareholders. Employees, however, usually face restrictions in both selling their options and shorting the stock of their firms, ${ }^{7}$ but it is not clear how important these restrictions are in aggregate. For example, employees who own stock can create the required hedge without shorting by selling a part of these holdings; index options or other derivative-based strategies can also be-and, in practice, frequently are-used to eliminate part of the risk in the options held; zero-cost collars are particularly popular in this regard. In any event, there is no one accepted way of identifying option value to the employee. The risk-neutral value offers a useful benchmark in this case, and, of course, this methodology has been extensively used in analyses of similar settings on this account (for example, the valuation of 
restricted stock grants in Longstaff [7]; the valuation of "high watermark" contracts in Goetzman, Ingersoll, and Ross [9]; or the valuation of non-standard compensation contracts in Johnson and Tian [12]).

\section{Rescindable vs Standard Options: A First Comparison}

A rescindable option is akin to a portfolio consisting of a standard call option and a contingent put which comes to life when the call is exercised, and which may only be exercised at time $T$; the strike of the put equals the strike on the original option plus the taxes owed on account of the initial exercise. Since the taxes owed depend on the stock price at which exercise occurs, rescindable options exhibit considerable path-dependence and must be valued by numerical methods. We describe the valuation procedure in Section 5.1 below. In one special case of interest, however, closed-form solutions are possible: we show in this section that when $r=0$ and the options are initially at- or out-of-the-money $\left(S_{0} \leq K\right)$, we can identify precisely the optimal exercise policies without specific assumptions about the stochastic process driving the stock price. This enables a sharp characterization of option values and option sensitivities. In particular, we establish in this section that

1. The net value to the employee of rescindable options is substantially higher than that of standard options on account of tax savings from timing the exercise decision appropriately.

2. The gross economic cost to the company of the two options is the same.

3. The tax shield provided by rescindable options is lower than that provided by standard options. However, if the company's marginal tax rate is lower than the employee's, the tax savings to the employee outweigh the tax shield loss to the company.

4. Rescindable options display substantially higher option sensitivities than standard options, thus dominating standard options from an incentive standpoint.

Although the results of this section are established for a special case, they indicate that the argument against rescission is far from obvious. Indeed, for this special case, these results establish that rescindable options comprehensively dominate the alternative of standard options. Section 4.1 identifies the closed-form solutions and discusses option values, while Section 4.2 presents the option sensitivities. 


\subsection{Option Values}

We introduce notation that will help simplify exposition. Let $C^{r}$ denote the value of the rescindable option to the employee, i.e., the discounted expected value of the net payoffs obtained under the optimal exercise and rescission strategies. Let $V^{r}$ denote the gross economic cost of this option to the company; $V^{r}$ is the discounted expected value of the gross payoffs under the optimal exercise and rescission strategies. Let $C^{n r}$ and $V^{n r}$ denote the corresponding values for the standard (non-rescindable) option. When we wish to emphasize the dependence of these quantities on the initial stock price, we shall write $C^{r}\left(S_{0}\right)$, etc. Finally, let $\xi\left(S_{0}\right)$ denote the value of a European call with a strike of $K$ maturing at date $T$ :

$$
\xi\left(S_{0}\right)=E_{0}^{*}\left[\left(S_{T}-K\right)^{+} \mid S_{0}\right] .
$$

Theorem 4.1 Suppose $r=0$ and $S_{0} \leq K$. Then:

1. Rescindable Options: $C^{r}\left(S_{0}\right)=V^{r}\left(S_{0}\right)=\xi\left(S_{0}\right)$.

2. Standard Options: $C^{n r}\left(S_{0}\right)=(1-\tau) \xi\left(S_{0}\right)$ and $V^{n r}\left(S_{0}\right)=\xi\left(S_{0}\right)$.

Theorem 4.1 states that while the gross cost to the company of the two options is the same, the employee receives this full value in the case of rescindable options, but only $(1-\tau)$ of the value in the case of the standard option. In particular, this implies that no taxes are paid by the employee in the case of rescindable options. The key to the proof of Theorem 4.1 lies in the following result which identifies optimal exercise policies under the two regimes.

Theorem 4.2 Under the conditions of Theorem 4.1:

1. With non-rescindable options, it is optimal to delay exercise of the option up to date $T$.

2. With rescindable options, it is optimal to exercise the option at date 0 .

Proof of Theorem 4.2 Suppose $r=0$. Consider the non-rescindable option first and pick any time $t<T$. Let $S_{t}$ denote the time- $t$ stock price. Since exercise triggers a tax liability on date $T$, the value of exercising on date $t$ at the stock price $S_{t}$ is given by

$$
\left(S_{t}-K\right)-\tau\left(S_{t}-K\right)^{+}
$$

We will show that this value is dominated by waiting until $T$ to exercise. To this end, we may clearly assume, without loss, that $S_{t} \geq K$ (if not, exercise at time $t$ has a negative value and 
cannot be optimal). Exercising at time $T$ results in a time- $T$ payoff of $(1-\tau)\left(S_{T}-K\right)^{+}$, so the time $-t$ value of this alternative is

$$
E^{*}\left[(1-\tau)\left(S_{T}-K\right)^{+} \| S_{t}\right]
$$

Now, $x^{+}=\max \{0, x\}$ is a convex function of $x$, so applying Jensen's inequality to (4.3) yields

$$
\begin{aligned}
E^{*}\left[(1-\tau)\left(S_{T}-K\right)^{+} \| S_{t}\right] & \geq(1-\tau)\left\{E^{*}\left[\left(S_{T}-K\right)\right]\right\}^{+} \\
& =(1-\tau)\left(S_{t}-K\right)
\end{aligned}
$$

which, from (4.2), says precisely that waiting till $T$ dominates early exercise at any time $t<T$. Note that the proof nowhere required the condition $S_{0} \leq K$ (or $S_{t} \leq K$ ); in particular, early exercise is not optimal for the non-rescindable option at any $t \in[0, T)$ regardless of $S_{t}$.

Now consider a rescindable option. Suppose the option is exercised at time $t$ at a stock price of $S_{t}$. Then, at date $t$, the option holder receives $\left(S_{t}-K\right)$, the depth in-the-money of the option at that point. In addition, on date $T$, the option holder faces the choice of rescinding this exercise decision. If the decision is not rescinded, there is a tax liability of $\tau \cdot\left(S_{t}-K\right)^{+}$. If the decision is rescinded, the option holder gives up a stock worth $S_{T}$ in exchange for the strike price $K$ and the elimination of the tax liability. It follows that rescission is optimal if and only if

$$
S_{T}-K-\tau\left(S_{t}-K\right)<0 .
$$

Thus, the total payoff to an option holder exercising at time $t$ may be represented as consisting of three components:

1. A payoff of $\left(S_{t}-K\right)$ at time $t$.

2. A tax liability of $\tau\left(S_{t}-K\right)^{+}$at date $T$.

3. A contingent payoff of $\left\{\left[K+\tau\left(S_{t}-K\right)^{+}\right]-S_{T}\right\}$ at time $T$, received in the event that $S_{T}<\left[K-\tau\left(S_{t}-K\right)^{+}\right]$.

Now, a payoff of $\left(S_{t}-K\right)$ at time $t$ is equivalent in present value terms to a payoff of $\left(S_{T}-K\right)$ at time $T$. It follows that the total payoffs to an option holder exercising on date $t$ are equivalent in present value terms to receiving the following payoff on date $T$ :

$$
\left\{\begin{array}{cl}
S_{T}-K-\tau\left(S_{t}-K\right)^{+}, & \text {if } S_{T} \geq\left[K+\tau\left(S_{t}-K\right)^{+}\right] \\
0, & \text { otherwise }
\end{array}\right.
$$


In particular, exercising at date 0 when $S_{0} \leq K$, results in the payoffs

$$
\left\{\begin{array}{cl}
S_{T}-K, & \text { if } S_{T} \geq K \\
0, & \text { otherwise }
\end{array}\right.
$$

It is immediate from a comparison of (4.6) and (4.7) that exercising at date 0 is never worse than exercising at any date $t>0$, and could be strictly better. This proves the second part of the theorem.

Proof of Theorem 4.1 From Theorem 4.2, a non-rescindable option will be held to maturity. Its payoffs on date $T$ are

$$
\left\{\begin{array}{cl}
(1-\tau)\left[S_{T}-K\right], & \text { if } S_{T} \geq K \\
0, & \text { otherwise }
\end{array}\right.
$$

Also from Theorem 4.2, a rescindable option will be exercised at date 0 and the exercise decision will be rescinded on date $T$ if and only if $S_{T}<K$, resulting in the time- $T$ payoffs (4.7). From (4.7), the initial value to the holder of the rescindable option is exactly $\xi\left(S_{0}\right)$ given by (4.1), while from (4.8), the holder of a non-rescindable option receives a fraction $(1-\tau)$ of this payoff. The gross payoffs in either case are equal to (4.7). This establishes the desired result.

Theorem 4.1 shows that for the same gross economic cost to the company of $\xi\left(S_{0}\right)$, rescindable options result in a tax savings for the employee of $\tau \xi\left(S_{0}\right)$. On the other hand, the company also receives a lower tax shield from the rescindable option-since the tax shield is equal to the depth in-the-money at the time of exercise, it is immediate from the description of the optimal strategies in the two cases that the company obtains no tax shield at all under the rescindable option, while the present value of the tax shield it obtains under the standard option is $\xi\left(S_{0}\right)$. Thus, if $\tau_{c}$ denotes the company's marginal tax rate, the tax savings to the company from using standard options is $\tau_{c} \cdot \xi\left(S_{0}\right)$.

From a pure cost standpoint, this implies that it pays for the company to use rescindable options whenever $\tau \geq \tau_{c}$. For two reasons, however, even this is an understatement of the case for rescindable options. First, if the company has inadequate current earnings, then the tax shield represents an asset whose discounted present value is less than $\tau_{c} \cdot \xi\left(S_{0}\right)$. Second, under the conditions considered here, the incentive features of rescindable options dominate those of standard options; we establish this now. 


\subsection{Comparison of Option Sensitivities}

As instruments for motivating employees, call options have two aspects. The first is that calls make money for the holders only when the stock price increases; thus, calls provide an directional incentive to increase the stock price. Second, like all options, calls are non-linear instruments whose convexity implies that they increase in value when uncertainty in the stock price (i.e., volatility) increases; consequently, options also induce risk-taking by the holders.

The strengths of the directional and volatility-increasing incentives provided by options are measured by the delta and vega, respectively. The delta measures the change in the net value of the option to the employee of a small change in the stock price, while the vega measures the change in net option value for a small change in the volatility of the stock. A higher delta implies a greater benefit to the employee from a dollar increase in the stock price, and therefore provides a greater directional incentive. A higher vega implies a higher benefit to the employee from an increase in volatility, so implies a higher risk-taking incentive. We will denote the delta and vega of the net option value by $\Delta$ and $\mathcal{V}$ respectively.

For the case studied in this section, it is trivial to show that both of these incentive measures are higher under rescindable options than standard options.

Theorem 4.3 Suppose $r=0$ and $S_{0}<K$. The delta and vega of the rescindable option at all points $t<T$ are higher than the corresponding values under the standard option. At any point we have

$$
\begin{aligned}
& \Delta(\text { Standard Option })=(1-\tau) \cdot \Delta(\text { Rescindable Option }) \\
& \mathcal{V}(\text { Standard Option })=(1-\tau) \cdot \mathcal{V}(\text { Rescindable Option })
\end{aligned}
$$

Proof We have shown in Theorem 4.2 that under these conditions, the rescindable option will be exercised immediately, while the standard option will be retained until date $T$; and that as a consequence, the payoffs of these options are given by (4.7) and (4.8), respectively. It is immediate that at any date $t \in[0, T)$, the rescindable option has the same value to the holder as the European call (4.1), while the standard option has a value equal to $(1-\tau)$ of this amount. Expression (4.9) follows.

The results of Sections 4.1 and 4.2 show that under specific conditions, rescindable options are superior to standard options. These results must be qualified by one observation: we have ignored possible capital gains taxes in our analysis. Formally handling the capital gains tax issue is next to impossible since we would have to model the investment decisions of the executive. However, the following informal arguments suggest that the superiority of rescindable options will 
still obtain, albeit in a more restricted set of circumstances. Any non-zero capital-gains tax rate will have a greater impact on rescindable options than standard options, since the former are exercised at a lower stock price. Thus, the net value to the employee will be (in the notation of Section 4.1) a fraction less than unity of $\xi\left(S_{0}\right)$. On the other hand, since capital gains tax rates are typically much lower than income tax rates, this value will still be higher than $(1-\tau) \xi\left(S_{0}\right)$, the value received by the holder of a standard option; and by extension, using the same arguments as in Theorem 4.3, its incentive features will also be better. If the executive's tax rate minus the capital gains rate exceeds the company's tax rate (or the discounted present value of the tax shield in case the company lacks sufficient earnings), the rescindable option will also dominate on the net cost front; but even if not, the higher incentive features of rescindable options indicate that as long as this differential is not too large, it would still be cheaper to achieve an aggregate delta or vega of a given amount using rescindable options than standard ones.

\section{Rescindable vs Standard Options: The General Case}

The first obstacle in extending the results of the previous section to the general case is identifing the optimal exercise strategy: if $r>0$, it is easily shown that both exercise decisions identified above may fail to be optimal:

Proposition 5.1 When $r>0$, neither conclusion of Theorem 4.2 may hold. In particular:

1. Regarding the standard option: For any $\tau>0$, if $r$ is large enough, it is optimal in at least some circumstances to exercise the option early.

2. Regarding the rescindable options: For any $\tau>0$, if $r$ is large enough, it is optimal in at least some circumstances to not exercise the option at time-0.

Proof Both results obtain from limiting arguments. Consider non-rescindable options first. The time- $t$ value of waiting until $T$ to exercise is

$$
(1-\tau) E^{*}\left[e^{-r(T-t)}\left(S_{T}-K\right)^{+} \| S_{t}\right]
$$

As $r \rightarrow \infty$, this value converges to $(1-\tau) S_{t}$. On the other hand, the value of immediate exercise at some point $t$ is $\left\{\left(S_{t}-K\right)-e^{-r(T-t)}\left(S_{t}-K\right)^{+}\right\}$. As $r \rightarrow \infty$, this converges to $\left(S_{t}-K\right)$. Thus, if $r$ is large enough, it is the case that for any $S_{t}$ such that $\tau S_{t}>K$, early exercise at $S_{t}$ is superior to waiting till $T$. 
Now consider rescindable options. Exercising and time- 0 followed by optimal rescission at time $-T$ is equivalent in present value to receiving the following payoffs at time- $T$ :

$$
\left\{\begin{array}{cl}
S_{T}-e^{r(T-t)} K, & \text { if } S_{T} \geq K \\
K-e^{r(T-t)} K, & \text { otherwise }
\end{array}\right.
$$

In turn, this is equivalent to receiving a portfolio consisting of (i) a standard call with strike $K$ and maturity $T$, and (ii) a certainty payoff of $K-e^{r(T-t)} K$. As $r$ increases without bound, the first component converges in value to $S_{0}$, but the second becomes arbitrarily negative. Thus, the sum is dominated at least by the alternative of waiting until time $T$ to exercise.

These arguments highlight a fundamental trade-off in the exercise decision for rescindable options between taxes and interest costs. Early exercise when the option is at- or out-of-themoney saves taxes for the option holder, but it requires payment of $K$ at exercise time. If the option is rescinded at $T$, the strike price is returned, but the interest on $K$ in the interim is foregone, as expression (5.1) highlights. As interest rates increase, one would intuitively expect the optimality of early exercise to decrease; as a consequence, the relative value from the option holder's standpoint of the rescindable option compared to the standard option should also decline.

We show that these intuitive arguments are correct. However, it is apparent from Proposition 5.1 that one cannot, in general, obtain closed-form solutions for the values of the two options. We resort therefore to numerical techniques as we explain below.

\subsection{Option Values}

We use a standard binomial tree model of stock price evolution to identify optimal exercise policies and option values. The computation of values for the standard option in this setting is a straightforward American option pricing problem that we solve by the usual backwards induction technique.

For rescindable options, matters are more complex. At each node in the binomial tree, we first compute the value to the employee of exercising at that node. Conceptually, this involves three steps. First, we identify the taxes due from exercise at that node. Then, we look at all terminal nodes that result from that node, and, using the information on taxes due, determine at which nodes rescission is optimal. Lastly, we take the present value of these terminal payoffs taking into account the optimal rescissions. This present value represents the value of exercise at that node. Using these values and backwards induction, we identify the optimal exercise strategy and thus initial option values to the employee.

To compute the gross cost to the company, we consider each node at which early exercise is optimal for the employee. For each terminal node resulting from such a node, we calculate the 
gross payoffs (including taxes) that result at maturity, taking into account optimal rescission at maturity. The present value of these terminal payoffs is the gross cost to the company at that node. Finally, taking present values over all nodes at which early exercise occurs delivers the gross initial cost to the company. Note that the difference between the net benefit to the employee and the gross cost to the company represents the present value of taxes paid on account of exercise.

The results from the computations are reported in Table 1 . The strike price in the tables is fixed at $K=100$ and the marginal tax rate $\tau$ is set to $40 \%$. The table considers 81 parameter combinations in all. The top panel of the table considers out-of-the-money options $\left(S_{0}=90\right)$ for three values of volatility $(\sigma=20 \%, 50 \%$, and $80 \%)$ and nine values for the interest rate (ranging from $0 \%$ to $10 \%)$. The second panel considers at-the-money options $\left(S_{0}=100\right)$ for the same ranges of values of volatility and interest rates, while the third panel considers in-the-money options $\left(S_{0}=110\right)$.

For each parameter configuration, four values are reported in the table: the value of the standard option to the employee ( $C^{n r}$ in the notation introduced earlier), the gross cost $V^{n r}$ of the standard option to the company, the value $C^{r}$ of the rescindable option to the employee, and finally the gross cost $V^{r}$ of the rescindable option to the company.

The numbers confirm the intuitive arguments made above. Consider at-the-money options, for example. The table shows that at low interest rates, immediate exercise is optimal in this case for rescindable options and no taxes are paid on account of exercise (the value to the employee and the gross cost to the company coincide). However, as interest rates rise, early exercise to reduce taxes becomes progressively less optimal and the net value of the rescindable option to the employee starts diverging from the gross cost to the company. As a consequence, the values of the rescindable and standard options get ever closer. At high interest rates, the values of the two options differ very little, both in terms of net value to the employee and gross cost to the company. At all interest rates, however, the value to the employee of the rescindable option is at least as high as the value of the corresponding standard option, while the gross cost to the company is equal or smaller for rescindable options. Similar patterns and conclusions obtain for the out-of-the-money and in-the-money options.

The table reveals some interesting properties of the options. For instance, while the value of the standard option increases with interest rates for the usual reasons, that of the rescindable option initially decreases as interest rates increase. In some cases (e.g., ATM options with volatility of $20 \%$ ), the values in the table begin to increase again at intermediate interest rates, but in others it continues to decrease even at the higher interest rates in the table. These patterns reflect the two opposing effects interest rates have on rescindable options: on the one hand, higher interest rates increase the cost of exercising early and subsequently rescinding the decision; on the other hand, higher interest rates create a higher risk-neutral drift for the stock. Note also that the level of volatility is crucial to the early exercise decision-for any given interest 
Table 1

This table summarizes the values of standard and rescindable options for a range of parameter values as explained in the text. The terms NRO and $\mathrm{RO}$ refer to standard (non-rescindable) and rescindable options, respectively. Val/Option (Emp) is the net-of-tax option value to the employee, while Cost/Option (Com) refers to the gross economic cost to the company of the option.

Option Values at Different Interest Rates \& Volatilities: OTM Options ( $\mathrm{S}=90 \mathrm{~K}=100 \mathrm{Tau}=40 \%$ )

\begin{tabular}{|c|c|c|c|c|c|c|c|c|c|c|c|}
\hline & & Interest Rates(\%) & 0.00 & 0.50 & 1.00 & 1.50 & 2.00 & 2.50 & 3.00 & 5.00 & 10.00 \\
\hline \multirow{4}{*}{ Vol=20\% } & \multirow{2}{*}{ NRO } & Val/Option (Emp) & 2.163 & 2.242 & 2.324 & 2.407 & 2.492 & 2.579 & 2.668 & 3.044 & 4.124 \\
\hline & & Cost/Option (Com) & 3.605 & 3.737 & 3.873 & 4.012 & 4.153 & 4.299 & 4.447 & 5.074 & 6.873 \\
\hline & \multirow{2}{*}{$\mathrm{RO}$} & Val/Option(Emp) & 3.605 & 3.454 & 3.317 & 3.266 & 3.230 & 3.198 & 3.166 & 3.221 & 4.132 \\
\hline & & Cost/Option (Com) & 3.605 & 3.454 & 3.444 & 3.508 & 3.511 & 3.486 & 3.460 & 4.226 & 6.481 \\
\hline & & & & & & & & & & & \\
\hline \multirow{4}{*}{ Vol $=50 \%$} & \multirow{2}{*}{ NRO } & Val/Option (Emp) & 8.691 & 8.788 & 8.885 & 8.983 & 9.082 & 9.181 & 9.281 & 9.684 & 10.726 \\
\hline & & Cost/Option (Com) & 14.485 & 14.646 & 14.807 & 14.970 & 15.133 & 15.297 & 15.462 & 16.130 & 17.852 \\
\hline & \multirow{2}{*}{ RO } & Val/Option (Emp) & 14.485 & 14.147 & 13.814 & 13.566 & 13.438 & 13.323 & 13.210 & 12.781 & 12.233 \\
\hline & & Cost/Option (Com) & 14.485 & 14.147 & 13.814 & 14.083 & 14.013 & 13.936 & 13.828 & 13.441 & 14.424 \\
\hline \multirow{4}{*}{ Vol $=80 \%$} & \multirow{2}{*}{ NRO } & |Val/Option (Emp) & 14.964 & 15.055 & 15.147 & 15.239 & 15.331 & 15.423 & 15.516 & 15.888 & 16.830 \\
\hline & & Cost/Option (Com) & 24.934 & 25.082 & 25.226 & 25.369 & 25.512 & 25.656 & 25.800 & 26.376 & 27.828 \\
\hline & \multirow{2}{*}{ RO } & Val/Option (Emp) & 24.940 & 24.590 & 24.243 & 23.898 & 23.557 & 23.218 & 22.935 & 22.407 & 21.404 \\
\hline & & Cost/Option (Com) & 24.940 & 24.590 & 24.243 & 23.898 & 23.557 & 23.218 & 23.926 & 23.801 & 24.351 \\
\hline
\end{tabular}

Option Values at Different Interest Rates \& Volatilities: ATM Options (S=K=100 Tau=40\%)

\begin{tabular}{|c|c|c|c|c|c|c|c|c|c|c|c|}
\hline \multicolumn{12}{|c|}{ Option Values at Different Interest Rates \& Volatilities: ATM Options (S=K=100 Tau=40\%) } \\
\hline & & Interest Rates(\%) & 0.00 & 0.50 & 1.00 & 1.50 & 2.00 & 2.50 & 3.00 & 5.00 & 10.00 \\
\hline \multirow{4}{*}{ Vol=20\% } & \multirow{2}{*}{ NRO } & Val/Option (Emp) & 4.662 & 4.801 & 4.943 & 5.086 & 5.232 & 5.381 & 5.531 & 6.152 & 7.838 \\
\hline & & Cost/Option (Com) & 7.769 & 8.002 & 8.238 & 8.477 & 8.721 & 8.968 & 9.218 & 10.253 & 13.064 \\
\hline & \multirow{2}{*}{ RO } & Val/Option (Emp) & 7.769 & 7.503 & 7.243 & 6.989 & 6.741 & 6.571 & 6.484 & 6.521 & 7.971 \\
\hline & & Cost/Option (Com) & 7.769 & 7.503 & 7.243 & 6.989 & 6.741 & 7.389 & 7.402 & 9.469 & 12.827 \\
\hline \multirow{4}{*}{ Vol $=50 \%$} & \multirow{2}{*}{ NRO } & (Val/Option (Emp) & 11.553 & 11.674 & 11.797 & 11.919 & 12.042 & 13.166 & 12.290 & 12792 & 14.080 \\
\hline & & Cost/Option (Com) & 19.255 & 19.456 & 19.658 & 19.861 & 20.065 & 20.269 & 20.474 & 21.303 & 23.425 \\
\hline & \multirow{2}{*}{$\mathrm{RO}$} & Val/Option (Emp) & 19.255 & 18.958 & 18.665 & 18.375 & 18.089 & 17.806 & 17.526 & 16.633 & 16.146 \\
\hline & & Cost/Option (Com) & 19.255 & 18.958 & 18.665 & 18.375 & 18.089 & 17.806 & 17.526 & 18.352 & 19.884 \\
\hline \multirow{4}{*}{$\mathrm{Vol}=80 \%$} & \multirow{2}{*}{ NRO } & Val/Option (Emp) & 18.192 & 18.300 & 18.408 & 18.516 & 18.625 & 18.733 & 18.482 & 19.280 & 20.386 \\
\hline & & Cost/Option (Com) & 30.319 & 30.482 & 30.645 & 30.808 & 30.972 & 31.135 & 31.298 & 31.952 & 33.591 \\
\hline & \multirow{2}{*}{$\mathrm{RO}$} & Val/Option (Emp) & 30.319 & 29.995 & 29.673 & 29.354 & 29.038 & 28.725 & 28.414 & 27.197 & 26.006 \\
\hline & & Cost/Option (Com) & 30.319 & 29.995 & 29.673 & 29.354 & 29.038 & 28.725 & 28.414 & 27.197 & 28.609 \\
\hline \multicolumn{12}{|c|}{ Option Values at Different Interest Rates \& Volatilities: ITM Options ( $\mathrm{S}=110 \mathrm{~K}=100 \mathrm{Tau}=40 \%$ ) } \\
\hline & & Interest Rates(\%) & 0.00 & 0.50 & 1.00 & 1.50 & 2.00 & 2.50 & 3.00 & 5.00 & 10.00 \\
\hline \multirow{4}{*}{ Vol $=20 \%$} & \multirow{2}{*}{ NRO } & Val/Option (Emp) & 8.629 & 8.825 & 9.021 & 9.220 & 9.420 & 9.621 & 9.824 & 10.649 & 12.784 \\
\hline & & Cost/Option (Com) & 14.382 & 14.708 & 15.036 & 15.367 & 15.700 & 16.036 & 16.374 & 17.748 & 21.307 \\
\hline & \multirow{2}{*}{ RO } & Val/Option (Emp) & 12.048 & 11.847 & 11.651 & 11.461 & 11.277 & 11.098 & 10.925 & 10.964 & 12.878 \\
\hline & & Cost/Option (Com) & 14.382 & 14.209 & 14.041 & 13.878 & 13.720 & 13.567 & 13.418 & 16.918 & 21.124 \\
\hline \multirow{4}{*}{ Vol $=50 \%$} & \multirow{2}{*}{ NRO } & |Val/Option (Emp) & 15.846 & 15.989 & 16.132 & 16.275 & 16.419 & 16.563 & 16.708 & 17.291 & 18.771 \\
\hline & & Cost/Option (Com) & 26.410 & 26.644 & 26.878 & 27.113 & 27.348 & 27.584 & 27.820 & 28.770 & 31.199 \\
\hline & \multirow{2}{*}{$\mathrm{RO}$} & Val/Option (Emp) & 24.318 & 24.051 & 23.786 & 23.525 & 23.268 & 23.013 & 22.762 & 21.787 & 20.756 \\
\hline & & Cost/Option (Com) & 26.410 & 26.148 & 25.890 & 25.634 & 25.382 & 25.133 & 24.886 & 23.932 & 26.577 \\
\hline \multirow{4}{*}{ Vol $=80 \%$} & \multirow{2}{*}{$\mathrm{NRO}$} & Val/Option (Emp) & 22.783 & 22.904 & 23.026 & 23.147 & 23.269 & 23.391 & 23.513 & 24.002 & 25.236 \\
\hline & & Cost/Option (Com) & 37.971 & 38.149 & 38.327 & 38.504 & 38.702 & 38.884 & 39.067 & 39.797 & 41.619 \\
\hline & \multirow{2}{*}{$\mathrm{RO}$} & Val/Option (Emp) & 36.123 & 35.818 & 35.515 & 35.215 & 34.917 & 34.622 & 34.330 & 33.186 & 31.092 \\
\hline & & Cost/Option (Com) & 37.971 & 37.667 & 37.365 & 37.065 & 36.768 & 36.474 & 36.182 & 35.041 & 34.929 \\
\hline
\end{tabular}


rate, early exercise becomes "more" optimal for rescindable options as volatility increases.

Table 1 suggests unambiguously that from the standpoint of net benefit to the employee and gross cost to the company, rescindable options dominate standard options. To identify the net costs of the two options to the company, we must identify the respective tax shields. The tax shield is based on depth-in-the-money at exercise time. Since the taxes paid by the employee are a fraction $\tau$ of the depth-in-the-money at exercise time, we can invert the present value of taxes paid to obtain the present value of the depths-in-the-money at exercise times and therefore the present value of the tax shield. Thus, the present value of the tax shield in the case of standard options is $\left(V^{n r}-C^{n r}\right) / \tau$ and in the case of rescindable options it is $\left(V^{r}-C^{r}\right) / \tau$. Observe

that since $V^{n r} \geq V^{r}$ and $C^{n r}<C^{r}$, the tax shield is always higher for standard options than rescindable ones. If $\tau_{c}$ denotes the corporate tax rate, the net costs of the options are given respectively by

$$
\left[V^{n r}-\tau_{c} \frac{1}{\tau}\left(V^{n r}-C^{n r}\right)\right] \text { and }\left[V^{r}-\tau_{c} \frac{1}{\tau}\left(V^{r}-C^{r}\right)\right] .
$$

Thus, taking the tax shield into account, the extra cost of using rescindable options for the company is

$$
V^{r}-V^{n r}-\tau_{c} \frac{1}{\tau}\left[V^{r}-V^{n r}-C^{r}+C^{n r}\right]
$$

while the increased benefit to the employee from using rescindable options is $C^{r}-C^{n r}$. It is immediate from these expressions that the increased benefit to the employee from using rescindable options exceeds the extra cost to the company whenever $\tau>\tau_{c}$. Thus, rescindable options offer a Pareto-superior alternative from the cost/value standpoint over standard options whenever the employee's marginal tax tax rate exceeds the company's. Once again, though, this understates the case for rescindable options: as we show in the next subsection, rescindable options also provide superior incentives in general, though the differences are not as dramatic as in the case of zero interest rates.

\subsection{Option Sensitivities}

Since we do not have closed-form solutions, option sensitivities must be calculated numerically by using the net option value for the employee. Table 2 provides a summary of the deltas for the same set of parameter configurations as in Table 1.

With some exceptions that occur at high interest rates and low volatilities, the deltas are higher under rescindable options than standard options, so rescindable options provide generally better directional incentives. The differences are particularly large for low interest rates when 


\section{TABLE 2}

I his table presents the deltas of the standard (non-rescindable) options and rescindable options, denoted in the table by $\mathrm{NRO}$ and $\mathrm{RO}$, respectively. The parameter configurations considered are the same as in Table 1.

\begin{tabular}{|c|c|c|c|c|c|c|c|c|c|c|}
\hline \multicolumn{11}{|c|}{ Option Deltas at Different Interest Rates \& Volatilities: OTM Options (S=90 K=100 Tau=40\%) } \\
\hline & Int Rates (\%) & 0.00 & 0.50 & 1.00 & 1.50 & 2.00 & 2.50 & 3.00 & 5.00 & 10.00 \\
\hline \multirow{2}{*}{ Vol=20\% } & $\mathrm{NRO}$ & 0.25 & 0.25 & 0.26 & 0.27 & 0.27 & 0.28 & 0.29 & 0.32 & 0.37 \\
\hline & $\mathrm{RO}$ & 0.42 & 0.43 & 0.37 & 0.32 & 0.31 & 0.32 & 0.32 & 0.30 & 0.32 \\
\hline \multirow{2}{*}{ Vol $=50 \%$} & NRO & 0.29 & 0.29 & 0.29 & 0.29 & 0.30 & 0.30 & 0.30 & 0.31 & 0.34 \\
\hline & $\mathrm{RO}$ & 0.48 & 0.48 & 0.49 & 0.38 & 0.37 & 0.36 & 0.37 & 0.38 & 0.39 \\
\hline \multirow{2}{*}{ Vol=80\% } & NRO & 0.32 & 0.32 & 0.33 & 0.33 & 0.33 & 0.33 & 0.33 & 0.34 & 0.36 \\
\hline & $\mathrm{RO}$ & 0.54 & 0.54 & 0.54 & 0.55 & 0.55 & 0.55 & 0.47 & 0.45 & 0.44 \\
\hline
\end{tabular}

\section{Option Deltas at Different Interest Rates \& Volatilities: ATM Options (S=K=100 Tau=40\%)}

\begin{tabular}{|c|c|c|c|c|c|c|c|c|c|c|}
\hline & Int Rates (\%) & 0.00 & 0.50 & 1.00 & 1.50 & 2.00 & 2.50 & 3.00 & 5.00 & 10.00 \\
\hline \multirow{2}{*}{ Vol $=20 \%$} & NRO & 0.32 & 0.32 & 0.33 & 0.34 & 0.35 & 0.35 & 0.36 & 0.38 & 0.43 \\
\hline & RO & 0.42 & 0.43 & 0.44 & 0.45 & 0.45 & 0.35 & 0.35 & 0.38 & 0.40 \\
\hline \multirow{2}{*}{ Vol $=50 \%$} & NRO & 0.36 & 0.36 & 0.36 & 0.36 & 0.37 & 0.37 & 0.37 & 0.38 & 0.40 \\
\hline & $\mathrm{RO}$ & 0.49 & 0.50 & 0.50 & 0.50 & 0.51 & 0.51 & 0.51 & 0.42 & 0.42 \\
\hline \multirow{2}{*}{ Vol $=80 \%$} & NRO & 0.39 & 0.39 & 0.39 & 0.40 & 0.40 & 0.40 & 0.40 & 0.41 & 0.42 \\
\hline & $\mathrm{RO}$ & 0.56 & 0.56 & 0.56 & 0.57 & 0.57 & 0.57 & 0.57 & 0.58 & 0.49 \\
\hline
\end{tabular}

\section{Option Deltas at Different Interest Rates \& Volatilities: ITM Options (S=110 K=100 Tau=40\%)}

\begin{tabular}{l|l|l|l|l|l|l|l|l|l|l|}
\hline Int Rates (\%) & 0.00 & 0.50 & 1.00 & 1.50 & 2.00 & 2.50 & 3.00 & 5.00 & 10.00 \\
\hline \multirow{2}{*}{ Vol=20\% } & NRO & 0.40 & 0.40 & 0.40 & 0.41 & 0.42 & 0.42 & 0.43 & 0.45 & 0.50 \\
\cline { 2 - 11 } & RO & 0.42 & 0.43 & 0.44 & 0.45 & 0.45 & 0.46 & 0.47 & 0.46 & 0.50 \\
\hline \multirow{2}{*}{ Vol=50\% } & NRO & 0.43 & 0.43 & 0.43 & 0.44 & 0.44 & 0.44 & 0.44 & 0.45 & 0.47 \\
\cline { 2 - 11 } & RO & 0.51 & 0.51 & 0.51 & 0.52 & 0.52 & 0.52 & 0.52 & 0.53 & 0.48 \\
\hline \multirow{2}{*}{ Vol=80\% } & NRO & 0.46 & 0.46 & 0.46 & 0.46 & 0.46 & 0.47 & 0.47 & 0.47 & 0.49 \\
\cline { 2 - 11 } & RO & 0.58 & 0.58 & 0.58 & 0.59 & 0.59 & 0.59 & 0.59 & 0.60 & 0.52 \\
\hline
\end{tabular}




\section{TABLE 3}

This table presents the vegas of the net option values for standard (non-rescindable) options and rescindable options, denoted in the table by $\mathrm{NRO}$ and $\mathrm{RO}$, respectively. The parameter configurations considered are the same as in Table 1.

\begin{tabular}{|c|c|c|c|c|c|c|c|c|c|c|}
\hline \multicolumn{11}{|c|}{ Option Vegas at Different Interest Rates \& Volatilities: OTM Options ( $\mathrm{S}=90 \mathrm{~K}=100 \mathrm{Tau}=40 \%$ ) } \\
\hline & Int Rates (\%) & 0.00 & 0.50 & 1.00 & 1.50 & 2.00 & 2.50 & 3.00 & 5.00 & 10.00 \\
\hline \multirow{2}{*}{ Vol=20\% } & NRO & 0.220 & 0.223 & 0.225 & 0.227 & 0.229 & 0.231 & 0.232 & 0.238 & 0.243 \\
\hline & $\mathrm{RO}$ & 0.367 & 0.362 & 0.340 & 0.311 & 0.307 & 0.307 & 0.309 & 0.268 & 0.230 \\
\hline \multirow{2}{*}{ Vol $=50 \%$} & NRO & 0.214 & 0.214 & 0.214 & 0.214 & 0.214 & 0.214 & 0.213 & 0.213 & 0.209 \\
\hline & $\mathrm{RO}$ & 0.357 & 0.357 & 0.356 & 0.330 & 0.327 & 0.325 & 0.325 & 0.325 & 0.308 \\
\hline \multirow{2}{*}{ Vol $=80 \%$} & NRO & 0.203 & 0.203 & 0.203 & 0.203 & 0.203 & 0.202 & 0.202 & 0.201 & 0.198 \\
\hline & $\mathrm{RO}$ & 0.339 & 0.339 & 0.338 & 0.337 & 0.337 & 0.336 & 0.323 & 0.317 & 0.303 \\
\hline \multicolumn{11}{|c|}{ Option Vegas at Different Interest Rates \& Volatilities: ATM Options ( $\mathrm{S}=\mathrm{K}=100 \mathrm{Tau}=40 \%$ ) } \\
\hline & Int Rates (\%) & 0.00 & 0.50 & 1.00 & 1.50 & 2.00 & 2.50 & 3.00 & 5.00 & 10.00 \\
\hline \multirow{2}{*}{ Vol=20\% } & NRO & 0.232 & 0.232 & 0.231 & 0.230 & 0.229 & 0.228 & 0.226 & 0.220 & 0.195 \\
\hline & $\mathrm{RO}$ & 0.387 & 0.386 & 0.385 & 0.383 & 0.381 & 0.354 & 0.348 & 0.276 & 0.212 \\
\hline \multirow{2}{*}{ Vol $=50 \%$} & NRO & 0.226 & 0.226 & 0.225 & 0.225 & 0.224 & 0.223 & 0.223 & 0.220 & 0.212 \\
\hline & $\mathrm{RO}$ & 0.377 & 0.376 & 0.375 & 0.374 & 0.373 & 0.372 & 0.371 & 0.351 & 0.321 \\
\hline \multirow{2}{*}{ Vol $=80 \%$} & NRO & 0.216 & 0.215 & 0.215 & 0.214 & 0.214 & 0.214 & 0.213 & 0.212 & 0.207 \\
\hline & $\mathrm{RO}$ & 0.359 & 0.358 & 0.357 & 0.357 & 0.356 & 0.355 & 0.354 & 0.350 & 0.336 \\
\hline \multicolumn{11}{|c|}{ Option Vegas at Different Interest Rates \& Volatilities: ITM Options (S=110 K=100 Tau=40\%) } \\
\hline & Int Rates (\%) & 0.00 & 0.50 & 1.00 & 1.50 & 2.00 & 2.50 & 3.00 & 5.00 & 10.00 \\
\hline \multirow{2}{*}{ Vol=20\% } & NRO & 0.244 & 0.240 & 0.251 & 0.233 & 0.229 & 0.225 & 0.221 & 0.205 & 0.162 \\
\hline & $\mathrm{RO}$ & 0.414 & 0.410 & 0.406 & 0.401 & 0.397 & 0.392 & 0.387 & 0.250 & 0.175 \\
\hline \multirow{2}{*}{ Vol $=50 \%$} & \begin{tabular}{|l|}
$\mathrm{NRO}$ \\
\end{tabular} & 0.237 & 0.236 & 0.235 & 0.234 & 0.233 & 0.232 & 0.231 & 0.226 & 0.214 \\
\hline & $\mathrm{RO}$ & 0.403 & 0.401 & 0.400 & 0.398 & 0.397 & 0.395 & 0.393 & 0.387 & 0.330 \\
\hline \multirow{2}{*}{ Vol $=80 \%$} & NRO & 0.225 & 0.224 & 0.224 & 0.223 & 0.223 & 0.222 & 0.222 & 0.220 & 0.214 \\
\hline & $\mathrm{RO}$ & 0.383 & 0.382 & 0.381 & 0.380 & 0.378 & 0.377 & 0.376 & 0.371 & 0.356 \\
\hline
\end{tabular}


the options are out-of-the-money. The behavior of the deltas of the rescindable options is also more complex than that of standard options. For example, the dual impact of the interest rate in determining rescindable option values that was highlighted in the previous section can also be seen in this table. For the standard option, option deltas increase as interest rates increase (loosely speaking, a higher rate of interest means a higher risk-neutral drift for the option which pushes it "more" into the money). However, for rescindable options, this behavior is not monotone: the delta typically increases with interest rates, then decreases, then increases again. Intuitively, at low interest rates, early exercise when the option is at- or out-of-the-money is optimal because the time value loss on the strike price is small; thus, the gross and net option values coincide. Over

this range of rates, the delta increases with interest rates. At higher interest rates, immediate exercise is no longer optimal, so the increase in the gross option value is larger than the increase in the net value. Thus, the delta declines. (Compare, for example, the behavior of rescindable option values and deltas at interest rates of $2 \%$ and $2.50 \%$ in Tables 1 and 2.)

Table 3 summarizes vegas for the two options for the same range of parametrizations as in the earlier tables. With a single exception now, the table shows that the vegas are higher for rescindable options than for standard options, and typically substantially so. Once again, the difference between the options is most pronounced at low interest rates, though in most cases, it remains substantial even at high interest rates. (Note also that, as with the delta, the sensitivities are higher for both options at high volatilities.) Thus, rescindable options generally provide better risk-taking incentives as well.

\section{Rescissions without Tax Cancellation}

The tax treatment of rescission is, as we explain in Section 6, somewhat uncertain since there is no explicit guidance from the Internal Revenue Service (IRS) on this topic. In this section, we examine the impact on the properties of rescindable options if rescission does not cancel the employee's tax liability.

Tables 4 through 6 present the option values and option sensitivities for this case. The tables consider the same parameter configurations as in Tables 1-3. Table 4 presents gross and net option values under the assumption that rescission does not cancel the tax liability created by the original exercise. Tables 5 and 6 present the option deltas and vegas for this case. The standard option is, of course, unaffected by this change, so the numbers described in Tables 4-6 for the standard option are the same as in Tables 1-3.

If interest rates are low and the option is at- or out-of-the-money, it is easy to see that this change in tax treatment will have no impact. Our earlier analysis showed that immediate exercise is optimal in these circumstances, under the assumption that rescission cancelled the 
Table 4

This table summarizes the values of standard and rescindable options for the same range of parameter values as in Table 1. The standard (nonrescindable) option values are the same as in table 1. The values of the rescindable options are computed assuming there is no forgiving of the tax upon rescission as explained in Section 6.

\begin{tabular}{|c|c|c|c|c|c|c|c|c|c|c|c|}
\hline \multicolumn{12}{|c|}{ Option Values at Different Interest Rates \& Volatilities: OTM Options ( $\mathrm{S}=90 \mathrm{~K}=100 \mathrm{Tau}=40 \%$ ) } \\
\hline & & Interest Rates(\%) & 0.00 & 0.50 & 1.00 & 1.50 & 2.00 & 2.50 & 3.00 & 5.00 & 10.00 \\
\hline \multirow{4}{*}{ Vol $=20 \%$} & \multirow{2}{*}{ NRO } & Val/Option(Emp) & 2.163 & 2.242 & 2.324 & 2.407 & 2.492 & 2.579 & 2.668 & 3.044 & 4.124 \\
\hline & & Cost/Option (Com) & 3.605 & 3.737 & 3.873 & 4.012 & 4.153 & 4.299 & 4.447 & 5.074 & 6.873 \\
\hline & \multirow{2}{*}{$\mathrm{RO}$} & Val/Option(Emp) & 3.605 & 3.454 & 3.302 & 3.155 & 3.094 & 3.056 & 3.026 & 3.115 & 4.124 \\
\hline & & Cost/Option (Com) & 3.605 & 3.454 & 3.302 & 3.363 & 3.474 & 3.486 & 3.460 & 4.846 & 6.873 \\
\hline \multirow{4}{*}{ Vol $=50 \%$} & \multirow[b]{2}{*}{ NRO } & |Val/Option (Emp) & 8.691 & 8.788 & 8.885 & 8.983 & 9.082 & 9.181 & 9.281 & 9.684 & 10.726 \\
\hline & & Cost/Option (Com) & 14.485 & 14.646 & 14.807 & 14.970 & 15.133 & 15.297 & 15.462 & 16.130 & 17.852 \\
\hline & \multirow{2}{*}{$\mathrm{RO}$} & Val/Option (Emp) & 14.485 & 14.147 & 13.814 & 13.483 & 13.156 & 12.832 & 12.511 & 11.977 & 11.330 \\
\hline & & Cost/Option (Com) & 14.485 & 14.147 & 13.814 & 13.483 & 13.156 & 12.832 & 12.511 & 13.402 & 16.045 \\
\hline \multirow{4}{*}{ Vol $=80 \%$} & \multirow{2}{*}{ NRO } & |Val/Option (Emp) & 14.964 & 15.055 & 15.147 & 15.239 & 15.331 & 15.423 & 15.516 & 15.888 & 16.830 \\
\hline & & Cost/Option (Com) & 24.934 & 25.082 & 25.226 & 25.369 & 25.512 & 25.656 & 25.800 & 26.376 & 27.828 \\
\hline & \multirow{2}{*}{$\mathrm{RO}$} & Val/Option (Emp) & 24.940 & 24.590 & 24.243 & 23.898 & 23.557 & 23.218 & 22.882 & 21.564 & 19.142 \\
\hline & & Cost/Option (Com) & 24.940 & 24.590 & 24.243 & 23.898 & 23.557 & 23.218 & 22.882 & 21.564 & 22.424 \\
\hline
\end{tabular}

Option Values at Different Interest Rates \& Volatilities: ATM Options ( $\mathrm{S}=\mathrm{K}=100 \mathrm{Tau}=40 \%)$

\begin{tabular}{|c|c|c|c|c|c|c|c|c|c|c|c|}
\hline & & Interest Rates(\%) & 0.00 & 0.50 & 1.00 & 1.50 & 2.00 & 2.50 & 3.00 & 5.00 & 10.00 \\
\hline \multirow{4}{*}{ Vol $=20 \%$} & \multirow{2}{*}{ NRO } & Val/Option (Emp) & 4.662 & 4.801 & 4.943 & 5.086 & 5.232 & 5.381 & 5.531 & 6.152 & 7.838 \\
\hline & & Cost/Option (Com) & 7.769 & 8.002 & 8.238 & 8.477 & 8.721 & 8.968 & 9.218 & 10.253 & 13.064 \\
\hline & \multirow{2}{*}{ RO } & Val/Option (Emp) & 7.769 & 7.503 & 7.243 & 6.989 & 6.741 & 6.499 & 6.262 & 6.300 & 7.838 \\
\hline & & Cost/Option (Com) & 7.769 & 7.503 & 7.243 & 6.989 & 6.741 & 6.499 & 6.262 & 9.546 & 13.064 \\
\hline \multirow{4}{*}{ Vol=50\% } & \multirow{2}{*}{ NRO } & Val/Option (Emp) & 11.553 & 11.674 & 11.797 & 11.919 & 12.042 & 13.166 & 12.290 & 12.792 & 14.080 \\
\hline & & Cost/Option (Com) & 19.255 & 19.456 & 19.658 & 19.861 & 20.065 & 20.269 & 20.474 & 21.303 & 23.425 \\
\hline & \multirow{2}{*}{ RO } & Val/Option (Emp) & 19.255 & 18.958 & 18.665 & 18.375 & 18.089 & 17.806 & 17.526 & 16.439 & 14.767 \\
\hline & & Cost/Option (Com) & 19.255 & 18.958 & 18.665 & 18.375 & 18.089 & 17.806 & 17.526 & 16.439 & 20.738 \\
\hline \multirow{4}{*}{ Vol=80\% } & \multirow{2}{*}{ NRO } & Val/Option (Emp) & 18.192 & 18.300 & 18.408 & 18.516 & 18.625 & 18.733 & 18.482 & 19.280 & 20.386 \\
\hline & & Cost/Option (Com) & 30.319 & 30.482 & 30.645 & 30.808 & 30.972 & 31.135 & 31.298 & 31.952 & 33.591 \\
\hline & \multirow{2}{*}{ RO } & Val/Option (Emp) & 30.319 & 29.995 & 29.673 & 29.354 & 29.038 & 28.725 & 28.414 & 27.197 & 24.333 \\
\hline & & Cost/Option (Com) & 30.319 & 29.995 & 29.673 & 29.354 & 29.038 & 28.725 & 28.414 & 27.197 & 24.333 \\
\hline
\end{tabular}

Option Values at Different Interest Rates \& Volatilities: ITM Options ( $\mathrm{S}=110 \mathrm{~K}=100 \mathrm{Tau}=40 \%)$

\begin{tabular}{|c|c|c|c|c|c|c|c|c|c|c|c|}
\hline \multicolumn{12}{|c|}{ Option Values at Different Interest Rates \& Volatilities: ITM Options ( $=110 \mathrm{~K}=100$ Tau=40\%) } \\
\hline & & Interest Rates(\%) & 0.00 & 0.50 & 1.00 & 1.50 & 2.00 & 2.50 & 3.00 & 5.00 & 10.00 \\
\hline \multirow{4}{*}{ Vol=20\% } & \multirow{2}{*}{$\mathrm{NRO}$} & Val/Option (Emp) & 8.629 & 8.825 & 9.021 & 9.220 & 9.420 & 9.621 & 9.824 & 10.649 & 12.784 \\
\hline & & Cost/Option (Com) & 14.382 & 14.708 & 15.036 & 15.367 & 15.700 & 16.036 & 16.374 & 17.748 & 21.307 \\
\hline & \multirow{2}{*}{ RO } & Val/Option (Emp) & 10.380 & 10.330 & 10.290 & 10.260 & 10.230 & 10.210 & 10.200 & 10.720 & 12.784 \\
\hline & & Cost/Option (Com) & 14.382 & 14.410 & 14.450 & 14.490 & 14.550 & 14.610 & 14.680 & 17.330 & 21.307 \\
\hline \multirow{4}{*}{ Vol $=50 \%$} & \multirow{2}{*}{$\mathrm{NRO}$} & Val/Option (Emp) & 15.846 & 15.989 & 16.132 & 16.275 & 16.419 & 16.563 & 16.708 & 17.291 & 18.771 \\
\hline & & Cost/Option (Com) & 26.410 & 26.644 & 26.878 & 27.113 & 27.348 & 27.584 & 27.820 & 28.770 & 31.199 \\
\hline & \multirow{2}{*}{ RO } & Val/Option (Emp) & 22.410 & 22.170 & 21.930 & 21.690 & 21.460 & 21.230 & 21.000 & 20.130 & 19.190 \\
\hline & & Cost/Option (Com) & 26.410 & 26.148 & 25.890 & 25.634 & 25.382 & 25.133 & 24.886 & 23.932 & 29.570 \\
\hline \multirow{4}{*}{ Vol $=80 \%$} & \multirow{2}{*}{ NRO } & Val/Option (Emp) & 22.783 & 22.904 & 23.026 & 23.147 & 23.269 & 23.391 & 23.513 & 24.002 & 25.236 \\
\hline & & Cost/Option (Com) & 37.971 & 38.149 & 38.327 & 38.504 & 38.702 & 38.884 & 39.067 & 39.797 & 41.619 \\
\hline & \multirow{2}{*}{ RO } & Val/Option (Emp) & 33.970 & 33.690 & 33.400 & 33.120 & 32.850 & 32.570 & 32.300 & 31.240 & 28.740 \\
\hline & & Cost/Option (Com) & 37.971 & 37.667 & 37.365 & 37.065 & 36.768 & 36.474 & 36.182 & 35.041 & 32.360 \\
\hline
\end{tabular}




\section{TABLE 5}

This table presents option deltas for standard (non-rescindable) and rescindable options under the assumption that there is no tax-forgivance in a recision as explained in Section 6 . The parameter configurations are the same as in Table 2, and the deltas of the non-rescindable options are the same as in Table 2.

\begin{tabular}{|c|c|c|c|c|c|c|c|c|c|c|}
\hline \multicolumn{11}{|c|}{ Option Deltas at Different Interest Rates \& Volatilities: OTM Options ( $\mathrm{S}=90 \mathrm{~K}=100 \mathrm{Tau}=40 \%)$} \\
\hline & Int Rates (\%) & 0.00 & 0.50 & 1.00 & 1.50 & 2.00 & 2.50 & 3.00 & 5.00 & 10.00 \\
\hline \multirow{2}{*}{ Vol $=20 \%$} & $\mathrm{NRO}$ & 0.25 & 0.25 & 0.26 & 0.27 & 0.27 & 0.28 & 0.29 & 0.32 & 0.37 \\
\hline & $\mathrm{RO}$ & 0.42 & 0.43 & 0.44 & 0.37 & 0.26 & 0.25 & 0.25 & 0.29 & 0.37 \\
\hline \multirow{2}{*}{ Vol $=50 \%$} & NRO & 0.29 & 0.29 & 0.29 & 0.29 & 0.30 & 0.30 & 0.30 & 0.31 & 0.34 \\
\hline & RO & 0.48 & 0.48 & 0.49 & 0.49 & 0.49 & 0.50 & 0.50 & 0.21 & 0.26 \\
\hline \multirow{2}{*}{$\mathrm{Vol}=80 \%$} & NRO & 0.32 & 0.32 & 0.33 & 0.33 & 0.33 & 0.33 & 0.33 & 0.34 & 0.36 \\
\hline & RO & 0.54 & 0.54 & 0.54 & 0.55 & 0.55 & 0.55 & 0.55 & 0.56 & 0.32 \\
\hline
\end{tabular}

\section{Option Deltas at Different Interest Rates \& Volatilities: ATM Options (S=K=100 Tau=40\%)}

\begin{tabular}{|l|l|l|l|l|l|l|l|l|l|l|}
\hline Int Rates (\%) & 0.00 & 0.50 & 1.00 & 1.50 & 2.00 & 2.50 & 3.00 & 5.00 & 10.00 \\
\hline \multirow{2}{*}{ Vol=20\% } & NRO & 0.32 & 0.32 & 0.33 & 0.34 & 0.35 & 0.35 & 0.36 & 0.38 & 0.43 \\
\cline { 2 - 11 } & RO & 0.34 & 0.35 & 0.36 & 0.37 & 0.38 & 0.39 & 0.40 & 0.39 & 0.43 \\
\hline \multirow{2}{*}{ Vol=50\% } & NRO & 0.36 & 0.36 & 0.36 & 0.36 & 0.37 & 0.37 & 0.37 & 0.38 & 0.40 \\
\cline { 2 - 12 } & RO & 0.40 & 0.40 & 0.41 & 0.41 & 0.42 & 0.42 & 0.43 & 0.44 & 0.43 \\
\hline \multirow{2}{*}{ Vol=80\% } & NRO & 0.39 & 0.39 & 0.39 & 0.40 & 0.40 & 0.40 & 0.40 & 0.41 & 0.42 \\
\cline { 2 - 11 } & RO & 0.45 & 0.46 & 0.46 & 0.46 & 0.47 & 0.47 & 0.47 & 0.48 & 0.51 \\
\hline
\end{tabular}

\section{Option Deltas at Different Interest Rates \& Volatilities: ITM Options (S=110 K=100 Tau=40\%)}

\begin{tabular}{l|l|l|l|l|l|l|l|l|l|l|}
\hline Int Rates (\%) & 0.00 & 0.50 & 1.00 & 1.50 & 2.00 & 2.50 & 3.00 & 5.00 & 10.00 \\
\hline \multirow{2}{*}{ Vol=20\% } & NRO & 0.40 & 0.40 & 0.40 & 0.41 & 0.42 & 0.42 & 0.43 & 0.45 & 0.50 \\
\cline { 2 - 11 } & RO & 0.26 & 0.27 & 0.28 & 0.29 & 0.30 & 0.31 & 0.32 & 0.40 & 0.49 \\
\hline \multirow{2}{*}{ Vol=50\% } & NRO & 0.43 & 0.43 & 0.43 & 0.44 & 0.44 & 0.44 & 0.44 & 0.45 & 0.47 \\
\cline { 2 - 12 } & RO & 0.32 & 0.32 & 0.33 & 0.33 & 0.34 & 0.34 & 0.35 & 0.37 & 0.48 \\
\hline \multirow{2}{*}{ Vol=80\% } & NRO & 0.46 & 0.46 & 0.46 & 0.46 & 0.46 & 0.47 & 0.47 & 0.47 & 0.49 \\
\cline { 2 - 11 } & RO & 0.37 & 0.37 & 0.37 & 0.38 & 0.38 & 0.39 & 0.39 & 0.40 & 0.44 \\
\hline
\end{tabular}




\section{TABLE 6}

This table presents option vegas for standard (non-rescindable) and rescindable options under the assumption that there is no tax-forgivance in a recision as explained in Section 6 . The parameter configurations are the same as in Table 3, and the vegas for standard options are the same as Table 3.

\begin{tabular}{|c|c|c|c|c|c|c|c|c|c|c|}
\hline \multicolumn{11}{|c|}{ Option Vegas at Different Interest Rates \& Volatilities: OTM Options (S=90 K=100 Tau=40\%) } \\
\hline & Int Rates (\%) & 0.00 & 0.50 & 1.00 & 1.50 & 2.00 & 2.50 & 3.00 & 5.00 & 10.00 \\
\hline \multirow{2}{*}{ Vol=20\% } & NRO & 0.220 & 0.223 & 0.225 & 0.227 & 0.229 & 0.231 & 0.232 & 0.238 & 0.243 \\
\hline & $\mathrm{RO}$ & 0.367 & 0.372 & 0.376 & 0.334 & 0.284 & 0.271 & 0.269 & 0.246 & 0.243 \\
\hline \multirow{2}{*}{ Vol $=50 \%$} & NRO & 0.214 & 0.214 & 0.214 & 0.214 & 0.214 & 0.214 & 0.213 & 0.213 & 0.209 \\
\hline & $\overline{\mathrm{RO}}$ & 0.357 & 0.357 & 0.357 & 0.356 & 0.356 & 0.356 & 0.340 & 0.278 & 0.233 \\
\hline \multirow{2}{*}{ Vol=80\% } & INRO & 0.203 & 0.203 & 0.203 & 0.203 & 0.203 & 0.202 & 0.202 & 0.201 & 0.198 \\
\hline & $\mathrm{RO}$ & 0.339 & 0.339 & 0.338 & 0.337 & 0.337 & 0.336 & 0.336 & 0.333 & 0.269 \\
\hline
\end{tabular}

\section{Option Vegas at Different Interest Rates \& Volatilities: ATM Options (S=K=100 Tau=40\%)}

\begin{tabular}{l|l|l|l|l|l|l|l|l|l|l|l|}
\hline \multicolumn{2}{|l|}{ Int Rates (\%) } & 0.00 & 0.50 & 1.00 & 1.50 & 2.00 & 2.50 & 3.00 & 5.00 & 10.00 \\
\hline \multirow{2}{*}{ Vol=20\% } & NRO & 0.232 & 0.232 & 0.231 & 0.230 & 0.229 & 0.228 & 0.226 & 0.220 & 0.195 \\
\cline { 2 - 10 } & RO & 0.387 & 0.386 & 0.385 & 0.383 & 0.381 & 0.379 & 0.377 & 0.255 & 0.195 \\
\hline \multirow{2}{*}{ Vol=50\% } & NRO & 0.226 & 0.226 & 0.225 & 0.225 & 0.224 & 0.223 & 0.223 & 0.220 & 0.212 \\
\cline { 2 - 11 } & RO & 0.377 & 0.376 & 0.375 & 0.374 & 0.373 & 0.372 & 0.371 & 0.366 & 0.267 \\
\hline \multirow{2}{*}{ Vol=80\% } & NRO & 0.216 & 0.215 & 0.215 & 0.214 & 0.214 & 0.214 & 0.213 & 0.212 & 0.207 \\
\cline { 2 - 11 } & RO & 0.359 & 0.358 & 0.358 & 0.357 & 0.356 & 0.355 & 0.354 & 0.350 & 0.339 \\
\hline
\end{tabular}

Option Vegas at Different Interest Rates \& Volatilities: ITM Options (S=110 K=100 Tau=40\%)

\begin{tabular}{|c|c|c|c|c|c|c|c|c|c|c|}
\hline & Int Rates (\%) & 0.00 & 0.50 & 1.00 & 1.50 & 2.00 & 2.50 & 3.00 & 5.00 & 10.00 \\
\hline \multirow{2}{*}{ Vol $=20 \%$} & NRO & 0.244 & 0.240 & 0.251 & 0.233 & 0.229 & 0.225 & 0.221 & 0.205 & 0.162 \\
\hline & $\mathrm{RO}$ & 0.406 & 0.399 & 0.392 & 0.385 & 0.378 & 0.370 & 0.352 & 0.245 & 0.167 \\
\hline \multirow{2}{*}{ Vol $=50 \%$} & NRO & 0.237 & 0.236 & 0.235 & 0.234 & 0.233 & 0.232 & 0.231 & 0.226 & 0.214 \\
\hline & RO & 0.395 & 0.393 & 0.391 & 0.389 & 0.387 & 0.386 & 0.384 & 0.376 & 0.247 \\
\hline \multirow{2}{*}{ Vol $=80 \%$} & NRO & 0.225 & 0.224 & 0.224 & 0.223 & 0.223 & 0.222 & 0.222 & 0.220 & 0.214 \\
\hline & RO & 0.375 & 0.374 & 0.373 & 0.371 & 0.370 & 0.369 & 0.368 & 0.362 & 0.349 \\
\hline
\end{tabular}


tax liability. However, since immediate exercise creates no tax liability here, it is obvious that immediate exercise continues to remain optimal. Thus, at all low interest rates and for at- and out-of-the-money options, rescindable options continue to do better in general than standard options.

As interest rates increase, however, the change in taxatation beings to have an impact. A comparison of Tables 1 and 4 shows that for at- and out-of-the-money options, immediate exercise is optimal for the rescindable option under the new tax regime even where it was not under the old regime. This is intuitive: if rescission will not cancel the tax liability, an added incentive exists to exercise early and avoid the liability. At very high interest rates, however, the opportunity cost of foregone interest on the strike price begins to dominate and the rescindable option looks indistinguishable from the standard option.

For in-the-money options, on the other hand, the effect of the tax change are more immediate. Taxes cannot be avoided by exercising early since the options are already in-the-money. At low interest rates, the exercise decisions are largely unaffected (the gross costs of the rescindable option are the same to the company in Tables 1 and 4), but, of course, the net receipts to the employee are now smaller. At high interest rates, however, early exercise becomes less optimal quickly and the difference between rescindable and standard options becomes less pronounced than in Table 1.

Tables 5 and 6 show that incentive features are also substantially affected by the tax change. Roughly put, in those circumstances where early exercise occurs under the rescindable option, the latter has better incentive features than the standard option. This is intuitive: with early exercise, the rescindable option is now equivalent to a unit of stock and a put, which by put-call parity is akin to a standard call; in contrast, the standard option is, because of taxes upon exercise, like a fraction of this call. However, at high interest rates especially, early exercise becomes inoptimal for the holder of the rescindable option, and as a consequence, there is a substantial drop in the option's incentive features, with standard options now doing better in many cases.

These results indicate that the general superiority of rescindable options established in earlier sections derives in substantial part from having taxes cancelled upon rescission. Without this, standard options compare quite well with their rescindable counterparts.

\section{Tax Treatment of Executive Options}

Most options held by executives in U.S. firms are "nonqualified options" for tax purposes. These options trigger a tax liability for the employee and a deduction for the firm on the date of exercise, based on the spread between the exercise price and the current stock price. For the employee, this amount is taxed as ordinary income; if he continues to hold the underlying stock for at least 
12 months, further appreciation (or decline) is taxed as a capital gain (or loss).

A minority of options, called "incentive stock options," receive special tax benefits. The option holder pays no tax at the time of exercise and capital gains tax only when the underlying shares are sold, with a tax basis equal to the exercise price. The firm receives no tax deduction. Stock acquired from exercising ISOs must be held at least one year past the exercise date and two years past the option award date. However, tax benefits from ISOs can be severely limited for certain option holders, because the option spread at exercise-which would ordinarily be untaxed-enters into the calculation for alternative minimum tax, which is subject to a $28 \%$ marginal rate for those whose incomes exceed certain limits. ISO holders can also convert their options to NQOs by selling the underlying stock before the end of the required holding period; this strategy avoids the AMT if the stock is sold in the same calendar year as the exercise.

\section{Tax Treatment of Rescission}

Recission becomes appealing if the underlying stock value declines substantially after the exercise date. Since the spread on the exercise date determines the ordinary income tax obligation for NQOs, as well as the possible AMT obligation for ISOs, falling stock prices after the exercise date could leave the former option holder with stock whose value is less than his tax obligation.

The tax treatment of rescission remains uncertain due to an absence of clear guidance from the Internal Revenue Service. No statutes in the U.S. Internal Revenue Code address the possibility of recission, nor has the IRS issued any non-precedential Private Letter Rulings on the topic. The closest relevant legal reference point is IRS Private Letter Ruling 9104039, issued in 1991 in a case involving a rescission of restricted stock awards. In that case, the company and its employees agreed to rescind the awards after realizing that the firm's accountants had given mistaken advice about the awards' impact on the company's income statement. The IRS held that the rescissions permitted employees to "disregard for federal income tax purposes" the original awards, so long as both events occurred in the same tax year.

In our research and conversations with compensation experts, we heard a variety of opinions about whether this reasoning would be followed in the case of stock option exercise rescission. At least two important differences exist from the situation described above: option exercise rescission would not be based on a mutual mistake about underlying facts at the time of the exercise, and the event being rescinded - the exercise, controlled by the employee-is somewhat different from the event in the restricted stock case-the award, controlled by the firm.

Instead of permitting rescission to wipe out existing tax obligations, the IRS has at least one clear alternative: it could simply leave the tax obligations related to the original exercise intact after rescission. This alternative motivates the analysis in Section 6 above. 


\section{International Tax Treatment of Executive Stock Options}

Outside the US, tax laws governing the treatment of options granted to employees are rather new and subject to frequent amendment. In many countries, the tax law is simply a copy of the US code. In the UK, France, and Germany, for example, the law is similar to that of the US: a tax liability is created the day option exercise occurs with the depth-in-the-money at exercise time being treated as ordinary income. Italian law is different in this regard with options being taxed only if they are in-the-money on the day of grant.

A few countries in which the compensation of employees using corporate securities is a recent phenomenon have drafted laws that attempt to avoid inefficiently influencing employees' behavior. In India, for example, the tax treatment of all employee stock options parallels the treatment of Incentive Stock Options in the US. There is no tax liability until the stock obtained through exercise is sold, no matter how much later than the option exercise this occurs. Further, sale of the stock triggers a capital gains tax, not an income tax. The Japanese tax code is similar to the Indian one with a tax liability arising only when the stock acquired through exercise is sold.

In other countries the tax code tends to follow the principles of US law but with individual twists. Israel, for example, does not currently have clear legislation regarding the tax treatment of employee stock options. However, a pending proposal favors the US treatment, but with the following adjustment: if during the six months following exercise of the option, the price of the stock is below ther price at exercise, rescission will be permitted with cancellation of the tax liability stemming from the original exercise.

\section{Conclusions}

Like the earlier practice of repricing (the lowering of strike prices on unexercised options following a decline in stock prices), rescissions have come in for considerable criticism from shareholder groups and institutional investors. Superficially, there appears to be some justification for this negative view: rescissions appear to reward employees following a decline in stock prices, and thereby to weaken the alignment of incentives between shareholders and employees.

Our analysis comparing the value and incentive properties of standard options to ones whose exercise decisions may be rescinded ("rescindable options") shows, however, that much of this fear is unfounded. Far from being an employee giveaway, rescindable options often enable Paretoimproving outcomes in which the employee and company obtain greater benefit from the option without weakening - and often strengthening-employee incentives. This apparently counterintuitive conclusion obtains from a "gaming" of tax laws which enables transferring the tax component of an option's payoff to the employee and, in some cases, also the company. 
On the other hand, we also find that much of the benefit offered by rescissions derives from its tax treatment. Under current US law, the depth in-the-money of an option at exercise time is taxed as ordinary income in the year of exercise, but these taxes are cancelled if the exercise decision is rescinded before the end of the tax year. If the tax treatment were amended so that rescissions do not lead to tax cancellation, we find that while rescindable options still do better than standard options in some situations, their attractiveness is much reduced. 


\section{Footnotes}

${ }^{1}$ See, e.g., Acharya, John, and Sundaram [2], Brenner, Sundaram, and Yermack [3], Chance, Kumar, and Todd [5], Chidambaram and Prabhala [6], Gilson and Vetsuypens [8], Johnson and Tian [12], or Saly [17].

${ }^{2}$ See, e.g., "New Corporate Perk: If the Stock Falls, Cancel Purchases," New York Times, 1/26/2001; or "Unlike Most Investors, Some Insiders can Cancel Unprofitable Stock Purchases," Wall Street Journal, 2/15/2001.

${ }^{3}$ This tax treatment applies to those employee stock options that are called "non-qualified." Options in the other category, "incentive stock options," do not incur a tax liability upon exercise, but only when the stock obtained through exercise is sold. See Section 7 for further details.

${ }^{4} \mathrm{~A}$ typical example of the reaction is this quote from a compensation consultant in a press report: "[Rescissions] are beyond a double standard. If you're going to let people rescind transactions, you've literally removed all the risk."

${ }^{5}$ The example ignores capital gains taxes that must be paid when the stock is sold and that are based on the difference between the stock price at the time of sale and the stock price at the time of option exercise. This is not a serious omission. Capital gains taxe rates are lower (often significantly so) than income taxes; thus, the early exercise incentives for rescindable options work in the same direction, and the rescindable option will continue to provide more value to the employee even after taking this into account.

${ }^{6}$ The no-dividends assumption is reasonable since rescission is a practice followed by troubled firms.

${ }^{7} \mathrm{~A}$ discussion of these and related issues may be found in Rubinstein [16]. 


\section{References}

[1] APB Opinion No. 25, "Accounting for Stock Issued to Employees," Accounting Principles Board, 1972.

[2] Acharya, V., K. John, and R. Sundaram (2000) On the Optimality of Resetting Executive Stock Options, Journal of Financial Economics 57(3), 2000.

[3] Brenner, M., R. Sundaram, and D. Yermack (1998) Altering the Terms of Executive Stock Options, Journal of Financial Economics 57(3), 2000.

[4] Carpenter, J. and B. Remmers (1998) Stock Price Performance Following Insider Option Exercise, mimeo, Department of Finance, New York University.

[5] Chance, D., R. Kumar, and R. Todd (2000) The "Repricing" of Executive Stock Options, Journal of Financial Economics 57, pp.129-154.

[6] Chidambaram, N. and N. Prabhala (2001) Executive Stock Option Repricing, Internal Governance Mechanisms, and Management Turnover, forthcoming, Journal of Financial Economics.

[7] Longstaff, F. (1995) How Much Can Marketability Affect Security Values? Journal of Finance 50, pp.1767-1774.

[8] Gilson, S. and M. Vetsuypens (1993) CEO Compensation in Financially Distressed Firms: An Empirical Analysis, Journal of Finance 48, pp.425-458.

[9] Goetzmann, M., J. Ingersoll, and S. Ross (1998) High Water Marks, NBER Working Paper 6413, National Bureau of Economic Research, Cambridge, MA.

[10] Hemmer, T., S. Matsunaga, and T. Shevlin (1996) Optimal Exercise and the Value of Employee Stock Options granted with a Reload Provision, mimeo, School of Business Administration, University of Washington.

[11] Hemmer, T., S. Matsunaga, and T. Shevlin (1997) An Empirical Examination of Incentives to Adopt Reload Employee Stock Option Plans, mimeo, School of Business Administration, University of Washington.

[12] Johnson, S. and Y. Tian (1999) The Value and Incentive Effects of Non-Traditional Executive Stock Option Plans, Journal of Financial Economics 57(3), 2000. pp.3-34.

[13] Matsunaga, S.R. (1995) The Effects of Financial Reporting Costs on the use of Employee Stock Options, The Accounting Review 70(1), pp.1-26. 
[14] Matsunaga, S.R., T. Shevlin and D. Shores (1992) Disqualifying Dispositions of Incentive Stock Options: Tax Benefits Versus Financial Reporting Costs, Journal of Accounting Research 30 (Supplement), pp.37-76.

[15] Murphy, K.J. (1999) Executive Compensation, in Handbook of Labor Economics Vol III, (Eds: O. Ashenfelter and D. Card), North Holland.

[16] Rubinstein. M. (1994) On the Accounting Valuation of Employee Stock Options, Journal of Derivatives, 1995.

[17] Saly, P.J. (1994) Repricing Executive Stock Options in a Down Market, Journal of Accounting and Economics 18, pp.325-356.

[18] Seyhun, H.N. (1992) The Effectiveness of Insider-Trading Sanctions, Journal of Law and Economics 35, pp.149-182.

[19] Statement of Financial Accounting Standards No. 123, "Accounting for Stock-Based Compensation," Financial Accounting Standards Board, October 1998.

[20] Yermack, D. (1995) Do Corporations Award CEO Stock Options Effectively?, Journal of Financial Economics 39, pp.237-269.

[21] Yermack, D. (1997) Good Timing: CEO Stock Option Awards and Company News Announcements, Journal of Finance 52(2), pp.449-476. 